\title{
Effects of an Elastic Hamstring Assistance Device During Downhill Running
}

\author{
by \\ Randy L Aldret ${ }^{1}$, Brittany A. Trahan ${ }^{1}$, Greggory Davis ${ }^{1}$, Brian Campbell ${ }^{1}$, \\ David M. Bellar ${ }^{1}$
}

The purpose of this study was to determine the appropriateness of using an elastic hamstring assistance device to reduce perceived levels of soreness, increase isometric strength, increase passive range of motion, and decrease biomarkers of muscle damage after eccentric exercise, specifically, downhill running. This study was conducted in a university exercise physiology laboratory placing sixteen apparently healthy males ( $\bar{X}=21.6 \pm 2.5$ years) into two groups using a pre-test/post-test design. Pre-intervention measures taken included participants' body height, body mass, body fat, capillary blood samples, VO2max, isometric hamstring strength at 45 and 90 degrees of flexion and passive hamstring range of motion. Post-intervention measures included blood biomarkers, passive range of motion, the perceived level of soreness and isometric strength. An analysis of normality of data was initially conducted followed by multivariate analysis of variance (MANOVA) of hamstring strength at 45 and 90 degrees of flexion, blood myoglobin and passive range of motion of the hamstrings. Statistically significant changes were noted in subject-perceived muscle soreness and isometric strength at 90 degrees at the 24-hour post-exercise trial measure between the two groups. Results would suggest the findings could be explained by the decrease in muscle soreness from utilizing the device during the exercise trial. Further research should be conducted to address sample size issues and to determine if the results are comparable on different surfaces.

Key words: soreness; isometrics; hamstring, myoglobin.

\section{Introduction}

The hamstring muscle group is composed of three muscles: the biceps femoris, the semitendinosus and the semimembranosus. Composed of mostly Type II muscle fibers, hamstring muscles produce motion in both the knee and hip joints (Bellar et al., 2014; Worrel and Perrin, 1992). The long head of the biceps femoris is responsible for hip extension and knee flexion, while the short head produces knee flexion. Along with the long head of the biceps femoris, the semitendinosus and semimembranosus are involved in both knee flexion and hip extension.

Hamstring injuries are thought to occur during the terminal phase of the gait cycle due to large eccentric forces necessary to arrest the swing of the lower leg in preparation for ground contact (Bellar et al., 2014). The most common injury was hamstring strain, which was prevalently found among those participating in speed-strength events that included sprints (Makaruk et al., 2010). Makaruk et al. (2010) identified many factors that increased the risk of hamstring strains including higher muscle tone, too high with regard to stiffness of the muscles when their extensibility was limited, disturbances in coordination between the main extremities (bilateral asymmetry) and between the quadriceps and the hamstring muscle groups. Muscle damage was the primary mechanism that contributed to muscle soreness and strength loss

1 - School of Kinesiology, University of Louisiana at Lafayette, Lafayette, LA, USA. 
that followed eccentric exercise (Eston et al., 1995). In another study of two subject groups, one with and one without a recent hamstring injury, it was demonstrated that the injury group had a significantly tighter hamstring and a decreased range of motion when compared to the uninjured group (Jonhagen et al., 1994). One additional finding revealed that the injury group had weaker eccentric contractions and weaker concentric contractions at slower velocities.

$\begin{array}{ccc}\text { During } & \begin{array}{c}\text { downhill running, the } \\ \text { predominant }\end{array} & \text { contraction } \\ \text { component }\end{array}$
characterized is the eccentric component (Cai et al., 2010). Lindstedt et al. (2001) describe eccentric contractions as both braking and storing elastic recoil energy during normal locomotion, which requires little metabolic energy, but high force production. Once the force exerted exceeds the force developed by the muscle, work is performed on the stretching muscle and the muscle absorbs mechanical energy. This is where the term "negative work" is derived from (Abbott et al., 1952). Much of the absorbed energy is usable and added to the active force produced on the subsequent stride. This subsequent stretchshortening cycle results in improved running economy by enrichment of power output in the subsequent contraction of up to $50 \%$ (Chen et al., 2009; Franks et al., 2012; Komi, 2000; Seyfarth et al., 2000). In this way, muscles act like springs that absorb and recover elastic energy. However, since muscles also produce their own force, any change in the normal pattern can result in muscle soreness if the nature or magnitude of force production changes significantly. This explains why eccentric activities that are novel can greatly increase muscle soreness and elevate biomarkers associated with muscle damage.

Eccentric muscle contractions were known to cause most muscle damage when compared to other types of contractions (Bellar and Judge, 2014; Bryner et al., 2004; Eston et al., 1995; Higashihara et al., 2010). Bird et al. (2014) noted that it was common for people to suffer from muscle soreness in the 24 to $72 \mathrm{~h}$ period following bouts of an exercise that was unfamiliar. This soreness was referred to as DOMS due to the fact that it was not apparent during the exercise or immediately after. When there was an occurrence of muscle soreness and damage, biomarkers that caused the damage were present. Going back as far as 1983, Schwane et al. showed significant increases in muscle soreness, plasma creatine kinease and lactate dehydrogenase with the downhill running group that were not present in the level-ground running control group. While studying biomarkers of muscle damage, including myoglobin, it was found that there were elevations in myoglobin that were evident following running events such as a marathon or half-marathon (Bird et al., 2014; Sorichter et al., 2001). This finding was an indication that running could have the potential to cause rhabdomyolysis, the death of muscle fibers, and muscle cell leakage (Simpson et al., 2006). Also, Bird (2014) found that over $90 \%$ of subjects assessed that ran a marathon and a halfmarathon had a significant elevation in serum myoglobin immediately and one-hour post-race. Pokora et al. (2014) acknowledged that only the eccentric exercise increased permeability in the myocyte membrane and that it was the cause of a sizable amount of muscle damage. It was concluded that the increase in creatine kinase was the result of mechanical stress and muscle damage (Pokora et al., 2014).

Higashihara et al. (2010) explained that hamstring muscles were often injured during high-speed or high-intensity activities. The reason for this is that the actions of the hamstring (hip flexion and extension of the knee) occur simultaneously and cause the hamstrings to lengthen considerably. In the late swing phase of the running gait cycle, the hamstrings are placed under extremely high loads due to them being elongated. Alonso et al. (2009) stated in their research that "individuals with less flexibility would have decreased contractile force production at longer muscle lengths". This finding was due to static flexibility being limited by the development of passive muscle tension at the end of the ROM.

Bellar et al. (2014) measured activation of the biceps femoris and the semitendinosus while the subject performed an isometric hamstring strength test at 45 and 90 degrees of knee extension with a novel hamstring assistance device. This protocol was designed to measure EMG readings at the previously stated angles at the following percentages of peak isometric force: $15,30,45$ and $60 \%$. There were significant changes at 90 degrees of flexion when the subject 
performed the exercise at $30 \%$ of peak isometric force. Significant differences were found at 45 degrees for 15 and $30 \%$ of peak isometric force. The hamstring assistance device produced positive benefits to the harm ratio (35:1 for the biceps femoris and 5:1 for the semitendinosus) due to lower muscle activation in the hamstring.

The purpose of this study was to further the knowledge about the function and physiological effects of an elastic hamstring assistance device. This device is attached to the participants around the waist and the calves; the waist attachment being similar to a weightlifting belt and the calf attachments being similar to a neoprene compression sleeve. There are four ring attachments on the posterior of the belt, two on the left and right each, and one attachment ring on the each calf sleeve. An elastic resistance band connects the two posterior belt rings to the calf ring on right and left sides individually. The elastic bands are long enough that they are taut while the participant is standing, and this tautness provides passive knee knee flexion at rest and deceleration support when running.

The device had been previously studied by Bellar et al. (2014) and determined to reduce the electromyography, or better known as EMG (electrical), signal from the muscle during knee flexion exercise. The present study aimed to examine the protective effects of this elastic hamstring assistance device during exercise known to promote muscle damage, notably downhill running.

\section{Material and Methods}

\section{Participants}

For the investigation, sixteen apparently healthy college males were recruited out of various kinesiology classes at a university in the south United States. Participants average age was 21.63 years $( \pm 2.5 \mathrm{yrs})$, with body height of 176.65 $\mathrm{cm}( \pm 7.28 \mathrm{~cm})$, and body mass of $78.74 \mathrm{~kg}( \pm 10.31$ $\mathrm{kg}$ ). The study group was physically active and engaged in regular exercise 4.67 days/week $( \pm .67$ days/weeks); the participants had low relative body fat of $15.74 \%( \pm 6.79 \%)$, and above average cardiovascular function with $\mathrm{VO}_{2 \max }$ of 48.4 $\mathrm{ml} / \mathrm{kg} / \mathrm{min}( \pm 5.49 \mathrm{ml} / \mathrm{kg} / \mathrm{min})$

The participants gave written informed consent and reported to the Human Performance Lab for an initial visit where anthropometric measures were collected. All participants gave written informed consent to take part in the study and the methods were reviewed and approved by the Institutional Review Board at the University of Louisiana at Lafayette.

\section{Procedures}

This investigation was conducted to determine the utility of an elastic hamstring assistive device to reduce the perceived level of soreness, increase isometric strength, increase passive range of motion, and decrease biomarkers of muscle damage after eccentric exercise, specifically, downhill running. During the initial visit, participants' demographics and physical characteristics data was collected. Body height and mass were determined via a physician's triple beam balance with stadiometer attachment, while the body fat percentage was evaluated via air displacement plethysmography (Bod Pod Gold Standard, Rome, Italy). Blood myoglobin measures were obtained by the fingerstick method. Passive range of motion was assessed about the hip joint at the greater trochanter to determine hamstring flexibility (Lin et al., 2014; Pereira et al., 2010). $\mathrm{VO}_{2 \max }$ was determined via indirect calorimetry (ParvoMedic TrueOne, Sandy UT) using a running protocol investigated by Pokora et al. (2014). Following $\mathrm{VO}_{2 \max }$ assessment, the participant was instructed on appropriate technique on a test of isometric hamstring strength at two different joint angles: 45 and 90 degrees of knee flexion. After the initial visit the participants were randomly assigned to one of the two groups. The first intervention group would not receive a treatment (i.e. would not run with the hamstring assistance device); the second group would use the assistive device for the exercise during the subsequent trial.

During the next visit, participants were asked to come into the lab a minimum of two hours post-prandial in the evening hours (5-7 $\mathrm{pm})$. The participants had second capillary blood samples collected upon arrival. They were then asked to run at a -10 percent grade for $40 \mathrm{~min}$ at a speed equal to $75 \%$ of their $\mathrm{VO}_{2 \max }$ speed on the level ground. One hour after the conclusion of the run, capillary blood was again collected and assessment of passive range of motion (goniometer) and isometric strength testing (load cell) were performed in a similar manner to the initial lab visit. Afterwards, the participant was 
fed a standard meal (pre-packaged at $\sim 600 \mathrm{kcal}$ ). The participants returned to the human performance lab the next morning (minimum 12 hours) to undergo passive range of motion testing, isometric hamstring strength testing and they had a capillary blood sample taken. All procedures were repeated a final time at 24 hours post downhill running exercise, at this point the study was concluded for the participant.

\section{$\mathrm{VO}_{2 \max }$ Assessment}

For this study, the $\mathrm{VO}_{2 \max }$ protocol was performed during the initial visit to establish the subjects' running speed for the intervention visit. All $\mathrm{VO}_{2}$ tests were conducted between the hours of $8 \mathrm{am}$ and $12 \mathrm{pm}$. During the $\mathrm{VO}_{2}$ test, carbon dioxide $\left(\mathrm{CO}_{2}\right)$ production, pulmonary ventilation and respiratory quotient were recorded breath-bybreath every $30 \mathrm{~s}$. Following the $\mathrm{VO}_{2 \max }$ test, the subjects were divided into two groups.

\section{Isometric Hamstring Strength Test}

The test was conducted in a seated position, with the foot tethered to a load cell (iLoad Pro, Loadstar Sensors, Fremont CA) via a lightweight cable in an open kinetic chain. This device had been used previously in research studies to capture isometric strength data (Bellar et al., 2015a, 2015b). The participant was instructed to pull against the cable maximally for $3 \mathrm{~s}$. Each leg was tested twice at each joint angle (45 and 90 degrees of knee flexion). There were a total of eight trials performed during the initial visit. The protocol was repeated in each subsequent visit after the intervention, 12 hours post-run and 24 hours post-run.

\section{Hamstring Flexibility Assessment}

This assessment was performed with the participant lying supine on an examination table, the researcher articulated the leg of the subject to cause hip flexion until the end of the range of motion was achieved; this angle was assessed via a goniometer (McHugh et al., 2012; Ogura et al., 2007). The protocol was repeated in each subsequent visit after running on the treadmill, 12 hours post-run and 24 hours post-run.

\section{Blood Collection}

After collection, capillary blood samples were transferred into a serum separator microcentrifuge tube and spun in a microcentrifuge to separate serum. The serum was drawn off into a separate microtube and frozen at -35 degrees Celsius. The pellet, capillary tube and original microcentrifuge tube were discarded as biohazardous waste. Once all samples were collected, they were thawed and myoglobin concentrations were determined via enzyme-linked immune-assay (ELISA, LSBio, Seattle WA) analysis. This form of the assay used a microtiter plate pre-coated with an antibody in which a competitive binding assay was performed and concentrations were determined colorimetrically.

\section{Subjective Rating of Post-Intervention Soreness}

Following the exercise trials and followups, all subjects were sent a rating scale via email asking them to rate their soreness in the hamstring muscle group during the 48 hours after the exercise trial. The scale was of a range of 1-10 with one being little to no soreness and ten being an extreme amount of hamstring muscle soreness.

\section{Statistical Analysis}

Data were analyzed for normality using Shapiro-Wilk tests. Multivariate analysis and repeated measures ANOVA was used to examine the relationship within and between the following variables: blood myoglobin, isometric strength, hamstring flexibility, and subjective measure of hamstring soreness. All data analysis was performed using JMP 12.0 (SAS Institute Inc, Cary NC).

\section{Results}

\section{Analysis of Normality}

After analysis it was determined that myoglobin levels were non-normally distributed. Therefore, these data were log transformed prior to further statistical analysis.

\section{Flexibility of the Hamstrings}

Measurement of passive range of motion (PROM) for the hamstring muscle group demonstrated positive changes for both groups, although none were statistically significant.

\section{Isometric Hamstring Strength}

The measurements for the right leg at 45 degrees of flexion recorded an increase for both groups. While these changes varied by group and time of measurement, they were not statistically significant $\left(\mathrm{F}_{3,12}=0.80, p=0.063\right)$. Measurement for the left leg at 45 degrees of extension followed the same pattern as the right leg as all within interactions for the data group were not statistically significant $\left(\mathrm{F}_{3,12}=0.23, p=0.467\right)$.

The results at 90 degrees of flexion for 
isometric hamstring strength did show a significant difference $\left(\mathrm{F}_{3,12}=1.03, p=0.032\right)$ between the left leg.

\section{Subjective Measure of Hamstring Soreness}

In the 48-hour period following the exercise trial, the participants were asked to rate the soreness in the hamstring muscle group only. Soreness was assessed using subjective appraisal of their pain using a visual pain scale model. Participants were asked to rate the pain on a scale of 1-10 with one being no soreness and ten being the worst pain ever experienced. One subject in the device group reported soreness higher than one, while the highest number reported by a member of the non-device group was eight. The reported soreness difference between the groups was found to be statistically significant $\left(\mathrm{F}_{1,15}=\right.$ $16.20, p=0.001)$.

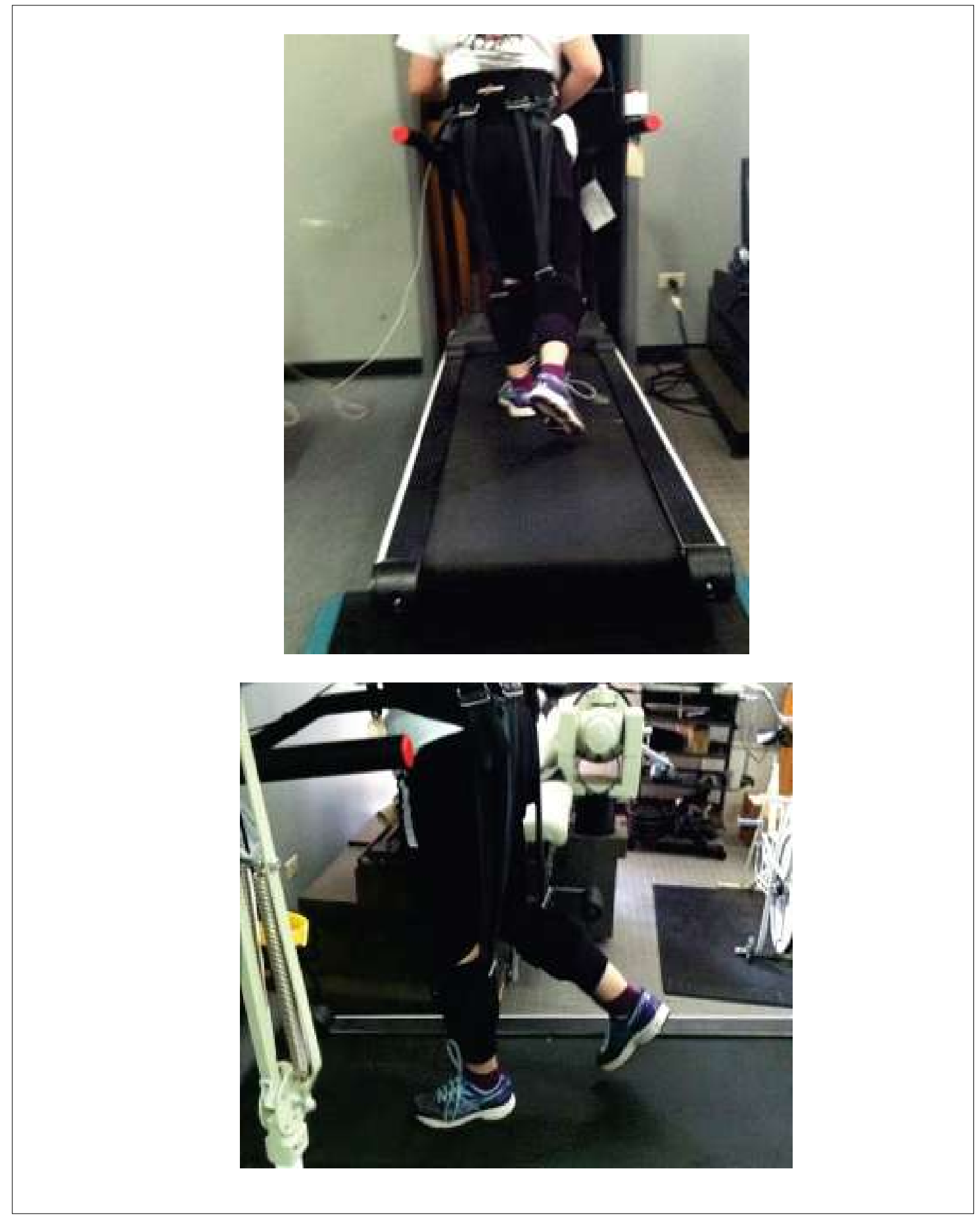

(c) Editorial Committee of Journal of Human Kinetics 


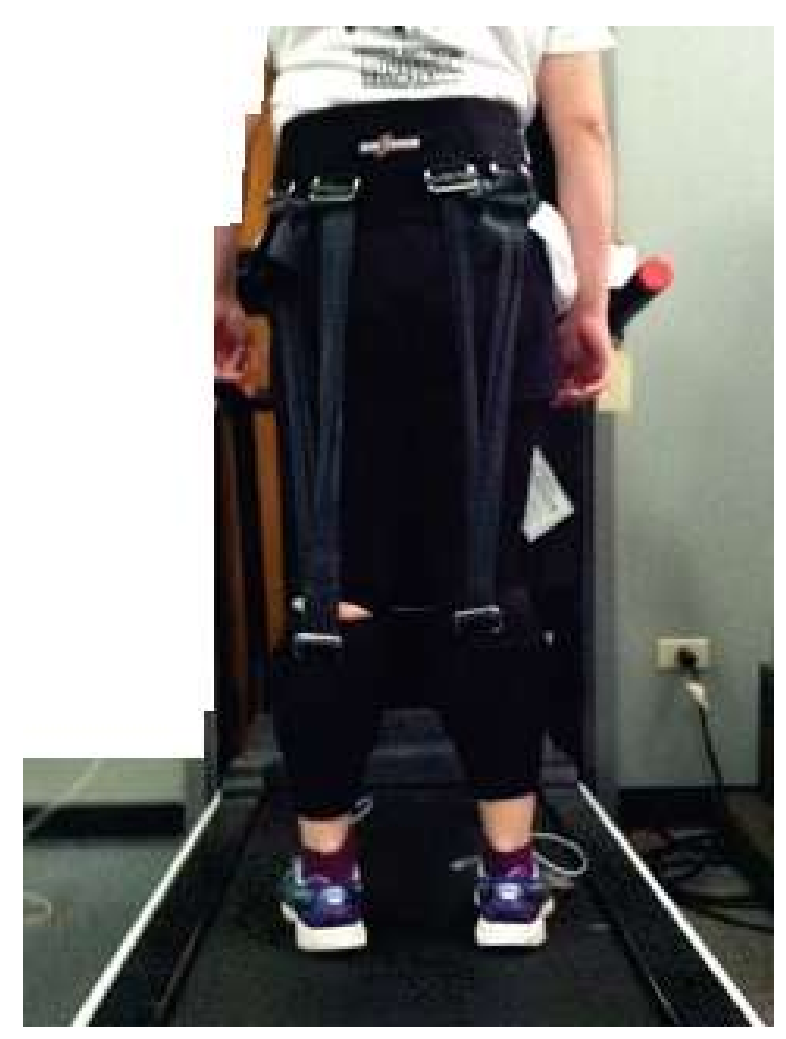

Table 1

Participants' Characteristics

\begin{tabular}{|c|c|c|c|c|c|c|c|}
\hline Group & $\mathrm{N}$ & Age (years) & $\begin{array}{c}\text { Body } \\
\text { Height }(\mathrm{m})\end{array}$ & $\begin{array}{l}\text { Body Mass } \\
(\mathrm{kg})\end{array}$ & Body Fat $\%$ & $\begin{array}{c}\mathrm{VO}_{2 \max } \\
(\mathrm{ml} / \mathrm{kg} / \min )\end{array}$ & $\begin{array}{c}\text { Running } \\
\text { Speed }(\mathrm{km} / \mathrm{h})\end{array}$ \\
\hline & 8 & & $178+07$ & $74.84+8.53$ & & $50.61 \pm 3.95$ & $10.59 \pm .90$ \\
\hline Non-Device & 8 & $23.00 \pm 2.45$ & $1.76 \pm .08$ & $82.65 \pm 10.96$ & $18.36 \pm 6.23$ & $46.19 \pm 6.14$ & $9.61 \pm 1.40$ \\
\hline
\end{tabular}

\section{Table 2}

Passive Hamstring Range of Motion

\begin{tabular}{|c|c|c|c|c|c|}
\hline Group & $\mathrm{n}$ & $\begin{array}{l}\text { Initial Hamstring } \\
\text { ROM } \\
\text { ( }{ }^{\circ} \text { of hip flexion } \\
\text { measured supine) }\end{array}$ & $\begin{array}{c}\text { 1hr Post } \\
\text { Hamstring ROM } \\
\left({ }^{\circ} \text { of hip flexion }\right. \\
\text { measured supine) }\end{array}$ & $\begin{array}{c}\text { 12hr Post } \\
\text { Hamstring ROM } \\
\text { ( }{ }^{\circ} \text { of hip flexion } \\
\text { measured supine) }\end{array}$ & $\begin{array}{c}\text { 24hr Post } \\
\text { Hamstring ROM ( } \\
\text { of hip flexion } \\
\text { measured supine) }\end{array}$ \\
\hline \multicolumn{6}{|l|}{ Right Leg } \\
\hline Device & 8 & $72.75^{\circ} \pm 17.12^{\circ}$ & $74.17^{\circ} \pm 12.91^{\circ}$ & $79.42^{\circ} \pm 5.82^{\circ}$ & $75.54^{\circ} \pm 17.07^{\circ}$ \\
\hline Non-Device & 8 & $75.96^{\circ} \pm 10.11^{\circ}$ & $74.88^{\circ} \pm 9.59^{\circ}$ & $79.33^{\circ} \pm 9.23^{\circ}$ & $76.54^{\circ} \pm 12.36^{\circ}$ \\
\hline \multicolumn{6}{|l|}{ Left Leg } \\
\hline Device & 8 & $73.79^{\circ} \pm 15.11^{\circ}$ & $72.08^{\circ} \pm 15.92^{\circ}$ & $80.25^{\circ} \pm 8.72^{\circ}$ & $78.38^{\circ} \pm 9.43^{\circ}$ \\
\hline Non-Device & 8 & $74.29^{\circ} \pm 13.19^{\circ}$ & $70.21^{\circ} \pm 10.28^{\circ}$ & $74.71^{\circ} \pm 7.45^{\circ}$ & $72.67^{\circ} \pm 14.14^{\circ}$ \\
\hline
\end{tabular}


Table 3

Isometric Hamstring Strength at $45^{\circ}$ of Knee Flexion

\begin{tabular}{lccccc}
\hline Group & $\mathrm{n}$ & $\begin{array}{c}\text { Initial Isometric } \\
\text { Strength (N) }\end{array}$ & $\begin{array}{c}\text { 1hr Post Isometric } \\
\text { Strength (N) }\end{array}$ & $\begin{array}{c}\text { 12hr Post Isometric } \\
\text { Strength (N) }\end{array}$ & $\begin{array}{c}\text { 24hr Post Isometric } \\
\text { Strength (N) }\end{array}$ \\
$\begin{array}{l}\text { Right Leg } \\
\text { Device }\end{array}$ & 8 & $377.68 \pm 100.30$ & $373.61 \pm 96.46$ & $405.67 \pm 155.64$ & $382.09 \pm 160.84$ \\
Non-Device & 8 & $380.98 \pm 131.34$ & $391.33 \pm 179.59$ & $335.18 \pm 130.11$ & $405.14 \pm 135.89$ \\
Left Leg & & & & & \\
Device & 8 & $368.07 \pm 117.36$ & $424.23 \pm 151.83$ & $421.12 \pm 114.12$ & $390.98 \pm 120.70$ \\
Non-Device & 8 & $426.02 \pm 162.50$ & $446.27 \pm 163.24$ & $414.11 \pm 174.02$ & $422.65 \pm 159.89$ \\
\hline
\end{tabular}

Table 4

Isometric Hamstring Strength at $90^{\circ}$ of Knee Flexion

\begin{tabular}{lccccc}
\hline Group & $\mathrm{n}$ & $\begin{array}{c}\text { Initial Isometric } \\
\text { Strength }(\mathrm{N})\end{array}$ & $\begin{array}{c}\text { 1hr Post Isometric } \\
\text { Strength }(\mathrm{N})\end{array}$ & $\begin{array}{c}\text { 12hr Post Isometric } \\
\text { Strength }(\mathrm{N})\end{array}$ & $\begin{array}{c}\text { 24hr Post Isometric } \\
\text { Strength }(\mathrm{N})\end{array}$ \\
\hline $\begin{array}{l}\text { Right Leg } \\
\text { Device }\end{array}$ & 8 & $254.40 \pm 108.55$ & $296.49 \pm 118.56$ & $347.75 \pm 136.86$ & $330.98 \pm 107.97$ \\
$\begin{array}{l}\text { Non-Device } \\
\text { Left Leg* }\end{array}$ & 8 & $333.56 \pm 103.43$ & $375.96 \pm 83.11$ & $350.26 \pm 100.82$ & $332.64 \pm 101.66$ \\
Device & 8 & $264.53 \pm 121.30$ & $303.64 \pm 125.18$ & $335.49 \pm 121.59$ & $316.43 \pm 129.57$ \\
Non-Device & 8 & $357.95 \pm 121.11$ & $381.70 \pm 107.44$ & $308.57 \pm 127.50$ & 339.20 \\
\hline
\end{tabular}

Table 5

Subjective Measure of Hamstring Muscle Soreness

\begin{tabular}{lcc}
\hline Group & $\mathrm{n}$ & $\begin{array}{r}\text { Soreness Scale }(1=\text { no soreness; } 10 \\
=\text { worst pain ever experienced })\end{array}$ \\
\hline Device & 8 & $1.25 \pm .71$ \\
Non-Device & 8 & $4.63 \pm 2.26^{*}, \#$ \\
\hline \multicolumn{2}{c}{${ }^{*}$ significant at $p \geq .05$, \# significant at $p \geq .01$}
\end{tabular}

Table 6

Blood Myoglobin concentration

\begin{tabular}{lccccc}
\hline Group & $n$ & $\begin{array}{c}\text { Pre-Exercise Blood } \\
\text { Myoglobin }(\mathrm{ng} / \mathrm{ml})\end{array}$ & $\begin{array}{c}\text { 1hr Post Blood } \\
\text { Myoglobin }(\mathrm{ng} / \mathrm{ml})\end{array}$ & $\begin{array}{c}\text { 12hr Post Blood } \\
\text { Myoglobin }(\mathrm{ng} / \mathrm{ml})\end{array}$ & $\begin{array}{c}\text { 24hr Post Blood } \\
\text { Myoglobin }(\mathrm{ng} / \mathrm{ml})\end{array}$ \\
Device & 8 & $7.47 \pm 6.29$ & $29.80 \pm 11.77$ & $17.23 \pm 10.74$ & $15.22 \pm 8.72$ \\
Non-Device & 8 & $85.39 \pm 141.42$ & $46.08 \pm 42.35$ & $18.27 \pm 19.04$ & $93.30 \pm 127.33$ \\
\hline
\end{tabular}




\section{Blood Myoglobin}

Samples were collected 1-hour, 12-hours, and 24-hours post-exercise. Analysis by repeated measures ANOVA found no main effect for group $\left(\mathrm{F}_{1,15}=2.43, p=0.140\right)$ nor interaction effect for treatment ${ }^{*}$ time $\left(\mathrm{F}_{1,15}=1.48, p=0.268\right)$.

\section{Discussion}

Upon examination of hamstring flexibility around the hip axis via passive range of motion (PROM) testing, a pattern begins to develop. For all four groups, there was a discernable pattern of decreased PROM at the 1-hour measure with peak measure at 12-hours post-exercise with regression to baseline at the 24-hour measurement. One trend in the data was the device group maintained a greater percentage of their postexercise PROM flexibility gains compared to the non-device group, but this difference was not statistically significant. Additionally, though the data was not statistically significant, all post exercise myoglobin levels that were above normal range $(0-85 \mathrm{ng} / \mathrm{ml})$ were observed in the nontreatment group, while all observed myoglobin levels in the device group were within normal range. When combining this pattern with the statistically significant increase in muscle soreness for the non-device group, the device's utility as a device to improve range motion in conjunction with a structured flexibility protocol begins to take shape. Previous studies have corroborated the assertion that compression affects muscle activation and function. An Arumugam et al.'s (2015a) study on pelvic compression belts demonstrated an ability to facilitate an effect on terminal range eccentric hamstring strength in groups with and without a previous hamstring injury. However, when this group attempted to replicate the study later in 2015 using competitive walkers, they found no change in EMG activity between groups (Arumugam et al., 2015b). While EMG activity increased in the gluteus maximus and decreased in the multifidus, which decreased stress on the pelvis, there was no significant difference between groups in hamstring EMG measures. This being said, there are other avenues being explored concurrently for hamstring compression devices. In an Australian study, compression material began to show promise in mapping eletromygraphic (EMG) activity during exercise for the purpose of force estimation in real-time (Belbasis et al., 2015).

One of the statistically significant results of this study notes the decrease in isometric force production in pre- vs post-measures for the nondevice group in the left leg at 90 degrees. Isometric testing followed a pattern of greatest loss in strength at the 12-hour post-exercise mark with rebound return to near or above baseline for all groups except the non-device left leg at 90 degrees. It should be noted that three of nondevice group measures did not return to baseline after 24 hours, but all four device groups' isometric measures returned to and exceeded baseline at 24-hours post-baseline. Due to this significant strength loss, there is evidence that the device provides protection to the hamstrings during activity. These findings support the efficacy of the assistance device use as an adjunct in the recovery and return-to-activity for athletes that suffer a hamstring injury.

The other significant finding regarding the device's ability to reduce subjective measures of soreness merits more investigation. With future studies of the device, it would be beneficial to look at the objective measures of soreness between groups with repeated measures. This would help determine the degree to which soreness inhibits strength production such as found in the left leg in this study. One final direction for future investigation would be the effects of the hamstring assistance device on an altering gait. The assistive device's ability to positively alter the gait to decrease soreness on any surface could demonstrate its utility improving an altered gait pattern due to muscular imbalances post-injury.

\section{Limitations}

Subjective observations from both the researchers and participants were noted as the protocol advanced. One of the subjects started to run without the heel strike phase of the gait. Another observation was that numerous subjects lost their footing due to running into the front of the treadmill. A final observation made was that most subjects self-reported soreness in the quadriceps, calves and glutes, with two subjects self-reporting soreness or swelling near the tibia (shin). A possible explanation to all of these observations could be due to the novelty of running downhill on a treadmill. 
While results from subjective data are not as reliable as objective measures, the information gathered does provide another avenue for future research. When examining the efficacy of the assistance device on muscle soreness measures, future studies should use a device such as an algometer, which would assist in quantifying patient perception of pain. This device would need to be applied at specific locations along all three muscles in the hamstring group to determine at where the soreness occurs and during which phase of the gait is effected, especially if downhill running is used in the future studies. If the algometer is employed, it should also be used in conjunction with the graphic pain rating scale we used in this study for easier and more consistent transition of patient pain scores.

Other avenues for future research with the hamstring assistance device should utilize EMG to measure muscle activation, especially during sprints on flat surfaces. In addition, delayed-onset and long-term analysis of muscle damage, specifically serum CK and LDH levels, will be useful in understanding the longitudinal efficacy of the hamstring assistance device.

\section{Conclusion}

In conclusion, this investigation suggests that the hamstring assistance device may be useful in maintaining force production in the hamstrings. When used during eccentric loading of the hamstrings, the device showed unique ability to decrease subject-reported, post-exercise soreness. Given the significant decrease in subjective measures of hamstring soreness in the device group, the device demonstrated potential as a tool in the conditioning of athletes pre- or post-injury to the hamstrings.

\section{References}

Abbott BC, Bigland B, Ritchie JM. The physiological cost of negative work. J Physiol, 1952; 117: 380-390

Alonso J, McHugh MP, Mullaney MJ, Tyler TF. Effect of hamstring flexibility on isometric knee flexion angle-torque relationship. Scandinavian J of Med \& Sci in Sports, 2009; 19: 252-256. doi: 10.1111/j.16000838.2008.00792.x

Arumugam A, Milosavljevic S, Woodley S, Sole G. Effects of external pelvic compression on isokinetic strength of the thigh muscles in sportsmen with and without hamstring injuries. J of Sci and Med in Sport, 2015a; 18: 283-288. doi: 10.1016/j.jsams.2014.05.009

Arumugam A, Milosavljevic S, Woodley S, Sole G. The effect of a pelvic compression belt on functional hamstring muscle activity in sportsmen with and without previous hamstring injury. Int $J$ of Sports Physical Therapy, 2015b; 10(3): 291-302

Belbasis A, Fuss F, Sidhu J. Muscle activity analysis with a smart compression garment. Procedia Engineering, 2015; 112: 163-168. doi: 10.1016/j.proeng.2015.07.193

Bellar D, LeBlanc NR, Campbell B. The effect of 6 days of alpha gylcerylphosphorylcholine on isometric strength. J Int Soc Sports Nutr, 2015a; 12: 42. doi: 10.1186/s12970-015-0103-x

Bellar D, LeBlanc NR, Judge LW. Examination of muscle activity with an elastic hamstring assistance device. J Health Res Rev, 2014; 1: 20-24. doi: 10.4103/2394-2010.143321

Bellar D, Marcus L, Judge LW. Validation and reliability of a novel test of upper body isometric strength. J Hum Kinet, 2015b; 47: 189-195

Bird SR, Linden M, Hawley JA. Acute changes to biomarkers as a consequence of prolonged strenuous running. Annals of Clin Biochem, 2014; 51(2): 137-150

doi: $10.1177 / 0004563213492147$

Bonnar BP, Deivert RG, Gould TE. The relationship between isometric contraction duration during holdrelax stretching and improvement of hamstring flexibility. J of Sports Med and Phys Fitness, 2004; 44(3): $258-261$ 
Bryner RW, Donley DA, Cutlip RG, Wirth O, Always SE. Effects of downhill treadmill running on uncoupling protein 3 mRNA expression. Int J of Sports Med, 2004; 25: 433-437. doi: 10.1055/s-2004820934

Burkett LN, Alvar B, Irvin J. Determining the optimal knee angle for testing maximal isometric hamstring peak torque on an isokinetic dynamometer. Int Sports J, 2002; 171-175

Cai ZY, Hsu CC, Su CP, Lin CF, Lin YA, Lin CL, Hsu MC. Comparison of lower limb muscle activation during downhill, level and uphill running. Isokinetics and Ex Sci, 2010; 18: 163-168 doi: 10.3233/IES2010-0379

Carpenter MR, Carpenter RL, Peel J, Zukley LM, Angelopoulou KM, Fischer I, Angelopoulos TJ, Rippe JM. The reliability of isokinetic and isometric leg strength measures among individuals with symptoms of mild osteoarthritis. J of Sports Med and Phys Fitness, 2006; 46(4): 585-589

Chavanelle V, Sirvent P, Ennequin G, Caillaud K, Montaurier C, Morio B, Boisseau N, Richard, R. Comparison of oxygen consumption in rats during uphill (concentric) and downhill (eccentric) treadmill exercise tests. J of Sport Sci and Med, 2014; 13: 689-694

Chen TC, Nosaka K, Lin M, Chen H, Wu C. Changes in running economy at different intensities following downhill running. J of Sport Sci, 2009; 27(11): 1137-1144

Eston RG, Mickleborough J, Baltzopoulos V. Eccentric activation and muscle damage: Biomechanical and physiological considerations during downhill running. Bri J of Sports Med, 1995; 29(2): 89-94

Franks KA, Brown LE, Coburn JW, Kersey RD, Bottaro M. Effects of motorized vs non-motorized treadmill training on hamstring/quadriceps strength ratios. J of Sports Sci and Med, 2012; 11: 71-76

Gottschall JS, Kram R. Ground reaction forces during downhill and uphill running. J of Biomech, 2005; 38(3): $445-452$

Hartig DE, Henderson JM. Increasing hamstring flexibility decreases lower extremity overuse injuries in military basic trainees. Am J of Sports Med, 1999; 27(2): 173-176

Higashihara A, Ono T, Kubota J, Okuwaki T, Fukufayashi T. Functional differences in the activity of the hamstring muscles with running speed. J of Sport Sci, 2010; 28(10): 1085-1092 doi: 10.1080/02640414.2010.494308

Jonhagen S, Nemeth G, Eriksson E. Hamstring Injuries in Sprinters: The role of concentric and eccentric hamstring muscle strength and flexibility. Am J of Sports Med, 1994; 22(2): 262-266

Komi PV. Stretch-shortening cycle: a powerful model to study normal and fatigued muscle. J Biomech, 2000; 33: 1197-1206

Lim K, Nam H, Jung, K. Effects on hamstring muscle extensibility, muscle activity, and balance of different stretching techniques. J of Phys Therapy Sci, 2014; 26: 209-213

Lindstedt SL, LaStayo TE, Reich TE. When Active Muscles Lengthen: Properties and Consequences of Eccentric Contractions. Physiology, 2001; 16(6): 256-261

Maeder M, Wolber T, Atefy R, Gadza M, Ammann P, Myers J, Rickli H. A nomogram to select the optimal treadmill ramp protocol in subjects with high exercise capacity: Validation and comparison with the Bruce protocol. J of Cardio Rehab, 2006; 26(1): 16-23

Makaruk H, Makaruk B, Sacewicz T. The effects of static stretching and isometric strength on hamstring strength and flexibility asymmetry. Pol J of Sport \& Tourism, 2010; 17: 153-156

McHugh MP, Johnson CD, Morrison RH. The role of neural tension in hamstring flexibility. Scand J of Med $\mathcal{E}$ Sci in Sports, 2012; 22: 164-169

doi: 10.1111/j.1600-0838.2010.01180.x

Ogura Y, Miyahara Y, Naito H, Katamoto S, Aoki J. Duration of static stretching influences muscle force production in hamstring muscles. J of Str and Cond Res, 2007; 21(3): 788-792 
Pereira BM, de Magalhães FA, Menzel HJ, de Melo JEP, Chagas MH. Correlation between clinical and laboratorial measurement of hamstring flexibility. Int Symposium on Biomech in Sports: Conference Proceedings Archive, 2010; 28: 1-4

Pokora I, Kempa K, Chrapusta SJ, Langfort J. Effects of downhill and uphill exercise of equivalent submaximal intensities on selected blood cytokine levels and blood creatine kinase activity. Biol of Sport, 2014; 31(3): 173-178

Schwane JA, Johnson SR, Vandenakker CB, Armstrong RB. Delayed-onset Muscular soreness and plasma CPK and LDH activities after downhill running. Med and Sci in Sports and Ex, 1983; 15(1): 51-56

Seyfarth A, Blickman R, van Leeuwen JL. Optimum take-off technique and muscle design for long jump. J Exp Biol, 2000; 302: 741-750

Simpson RJ, Florida-James GD, Whyte GP, Guy K. The effects of intensive, moderate and downhill treadmill running on human blood lymphocytes expressing the adhesion/activation molecules CD54 (ICAM-1), CD18 ( $\beta_{2}$ integrin) and CD53. Eur J of App Phys, 2006; 97: 109-121 doi: 10.1007/s00421-006-0146-4

Sorichter S, Mair J, Koller A, Calzolari C, Huonker M, Pau B, Puschendorf B. Release of muscle proteins after downhill running in male and female participants. Scand J of Med E Sci in Sports, 2001; 11: 28-32

Worrel TW, Perrin DH. Hamstring muscle injury: The influence of strength, flexibility, warm-up, and fatigue. J of Ortho \& Sports Physl Therapy, 1992; 16(1): 12-18

\section{Corresponding author:}

\section{Randy L. Aldret, EdD, ATC, LAT}

Assistant Professor and Director, Athletic Training Program

School of Kinesiology

225 Cajundome Blvd.

Lafayette, LA 70506

Phone: (337) 482-5681

Fax: (337) 482-6278

E-mail: raldret@louisiana.edu 